\title{
Genetically Informed Regression Analysis: Application to Aggression Prediction by Inattention and Hyperactivity in Children and Adults
}

\author{
Dorret I. Boomsma ${ }^{1,2}$ - Toos C. E. M. van Beijsterveldt ${ }^{1} \cdot$ Veronika V. Odintsova $^{1,2} \cdot$ Michael C. Neale $^{3}$. \\ Conor V. Dolan ${ }^{1,2}$
}

Received: 12 July 2020 / Accepted: 6 October 2020 / Published online: 1 December 2020

(c) The Author(s) 2020

\begin{abstract}
We present a procedure to simultaneously fit a genetic covariance structure model and a regression model to multivariate data from mono- and dizygotic twin pairs to test for the prediction of a dependent trait by multiple correlated predictors. We applied the model to aggressive behavior as an outcome trait and investigated the prediction of aggression from inattention (InA) and hyperactivity (HA) in two age groups. Predictions were examined in twins with an average age of 10 years $(11,345$ pairs), and in adult twins with an average age of 30 years (7433 pairs). All phenotypes were assessed by the same, but ageappropriate, instruments in children and adults. Because of the different genetic architecture of aggression, InA and HA, a model was fitted to these data that specified additive and non-additive genetic factors (A and D) plus common and unique environmental (C and E) influences. Given appropriate identifying constraints, this ADCE model is identified in trivariate data. We obtained different results for the prediction of aggression in children, where HA was the more important predictor, and in adults, where InA was the more important predictor. In children, about $36 \%$ of the total aggression variance was explained by the genetic and environmental components of HA and InA. Most of this was explained by the genetic components of HA and InA, i.e., $29.7 \%$, with $22.6 \%$ due to the genetic component of HA. In adults, about $21 \%$ of the aggression variance was explained. Most was this was again explained by the genetic components of InA and HA (16.2\%), with 8.6\% due to the genetic component of InA.
\end{abstract}

Keywords Inattention $\cdot$ Hyperactivity $\cdot$ Aggression $\cdot$ Genetic and environmental prediction $\cdot$ Regression $\cdot$ Structural equation model

Edited by David Evans.

Electronic supplementary material The online version of this article (https://doi.org/10.1007/s10519-020-10025-9) contains supplementary material, which is available to authorized users.

Dorret I. Boomsma

di.boomsma@vu.nl; c.v.dolan@vu.nl

$1 \quad$ Netherlands Twin Register, Department of Biological Psychology, Vrije Universiteit, Amsterdam, The Netherlands

2 Amsterdam Public Health (APH) and Amsterdam Reproduction and Development Research Institutes, Amsterdam, The Netherlands

3 Departments of Psychiatry and Human \& Molecular Genetics, Virginia Institute for Psychiatric and Behavioral Genetics, Virginia Commonwealth University, 1-156, P.O. Box 980126, Richmond, VA 23298-0126, USA

\section{Introduction}

Multivariate extensions of the classical twin design, that rest on trait and cross-trait comparisons of resemblances in mono- and dizygotic (MZ and DZ) twins, allow for inferences regarding pleiotropy and correlated environmental effects (Martin and Eaves 1977), the direction of causation between correlated traits (Heath et al. 1993; Duffy and Martin 1994), the moderation of genetic and environmental effects (Purcell 2002), and the analysis of the dimensionality of psychological (psychometric) instruments (Franić et al. 2013). In this contribution, we present an extension of the multivariate twin design that we developed to address questions about prediction of an outcome trait by multiple correlated variables. The model we present involves simultaneously fitting a multivariate genetic covariance structure model to estimate genetic (A, D) and environmental $(\mathrm{C}, \mathrm{E})$ variance matrices, and conducting the regression analyses 
based on the genetic (A, D, or A+D) and environmental (C, $\mathrm{E}$, or $\mathrm{C}+\mathrm{E}$ ) covariances.

We applied the model to measures of aggression, inattention, and hyperactivity that were collected in Dutch twins aged approximately 10 years, and in adult twins. Earlier research has indicated that aggression in children is influenced by genetic and common environmental factors (e.g., Porsch et al. 2016), while measures of attention deficithyperactivity disorder (ADHD), inattention, and hyperactivity tend to show strong evidence of non-additive genetic (dominance) influences (Derks et al. 2009). We therefore also investigated the conditions under which a variance decomposition model with both genetic dominance and common environmental influences could be fitted to the data. In univariate applications of the classical twin design, it is hardly ever possible to identify the contributions of both common environmental (C) factors and genetic dominance (D). Ozaki et al. (2011) presented an ACDE model using non-normal Structural Equation Modeling (nnSEM), that includes higher order moments as well as 1st- and 2ndorder moments, in which identification is achieved when not all four (ADCE) latent factors are distributed normally. We focus on identification in multivariate twin data, where identifying constraints can be formulated which allow for estimation of contributions from $\mathrm{D}$ and $\mathrm{C}$ factors in addition to $\mathrm{A}$ and $\mathrm{E}$ factors.

We considered the prediction of aggressive behavior by two dimensions of ADHD. ADHD is a neurobiological disorder that is characterized by symptoms of inattention and of hyperactivity/impulsivity, which may manifest in children and in adults. In children, positive associations have been found between broadly defined quantitative measures of aggression and ADHD and attention problems (Biederman et al. 1991; Jensen et al. 1997; Connor et al. 2010; Bartels et al. 2018, see: https://www.action-euproject.eu/ ComorbidityChildAggression), and negative associations with academic performance (e.g., Hinshaw, 1992; Hinshaw et al. 2006; Vuoksimaa et al. 2020).

Individual differences in aggression and ADHD are strongly influenced by genetic factors (Derks et al. 2009; Hamshere et al. 2013; Faraone and Larsson, 2019; Odintsova et al. 2019). Studies of the etiology of the association between aggression and ADHD indicated that these associations were largely explained by pleiotropic genetic factors. Hur (2015) presented a review of twin studies on hyperactivity/inattention and Conduct Problems, which showed moderate to high (0.17-0.68) phenotypic correlations, and high genetic correlations (0.43-1.0). Based on a systematic review, Andersson et al. (2020) reported a genetic correlation between externalizing symptoms and ADHD of 0.49 (CI 0.37-0.61). These findings are consistent with the substantial genetic correlation between aggression and $\mathrm{ADHD}(\mathrm{rg}=1.00, \mathrm{SE}=0.07)$ that was estimated in a recent meta-analysis of genome-wide association studies of childhood aggression and ADHD (Ip et al. 2019).

Compared to the many studies on aggression and ADHD, a smaller number of analyses have focused on the relationship between aggression and hyperactivity/impulsivity or aggression and inattention. A comprehensive literature review and meta-analysis of studies in children, adolescents and adults on ADHD symptom dimensions indicated that aggressive behavior, and more generally externalizing disorders, are more strongly associated with hyperactivity/ impulsivity than with inattention (Willcutt et al. 2012). The developmental trajectories of inattention and hyperactivity are different; young children are more likely to display hyperactive behaviors, while in middle childhood inattentive symptoms become more apparent and tend to persist into adulthood (Franke et al. 2018). Most studies of the association between aggression and ADHD subscales (see Willcutt et al. Supplementary Table 9) were done in children. The few publications in adults found no evidence that the associations of externalizing disorders with inattention and with hyperactivity differ.

Inattention and hyperactivity are not independent (e.g., Sokolova et al. 2016). Dolan et al. (2020) employed the classical twin design to analyze the correlation structure among measures of inattention and hyperactivity at the phenotype, genetic and environmental level. Inattention and hyperactivity were assessed by a variety of instruments. They concluded that the strong, broad-sense, genetic effects on inattention and hyperactivity are substantially correlated, regardless of instrument or rater.

Thus, when considering questions such as whether the association with aggression is stronger for inattention than for hyperactivity, we need to take into consideration that these two dimensions are not independent, e.g., there may be genetic pleiotropy, and that associations may differ across age groups. In this contribution, we investigated the differences between inattention and hyperactivity as predictors of aggression in a genetic design, analyzing data from $\mathrm{MZ}$ and DZ twins.

\section{Methods}

\section{Young Participants}

The Young Netherlands Twin Register (YNTR) recruits newborn twins and multiples, and follows these children through development by survey studies and dedicated projects in subgroups (Boomsma et al. 2002; van Beijsterveldt et al. 2013; Ligthart et al. 2019). Recruitment of young twins began in 1987 and is ongoing. For the present study, we analyzed data on aggression, hyperactivity and inattention by maternal ratings of twins who were on average 
10 years old (mean: 9.94 years; SD: 0.51 ). The twins were born between 1986 and 2006. In the YNTR, data on aggression were collected from 1995 onwards, and were available for all birth cohorts; data collection for hyperactivity and inattention began later, in 2001, so some twin pairs have incomplete phenotype information. There were 11,345 twin pairs (36\% MZ). Table 2 summarizes the total number of participants and the number of missing data by twin member and phenotype.

\section{Adult Participants}

The Adult Netherlands Twin Register (ANTR) began longitudinal data collection by surveys in 1991 from adolescent and adult twins and their relatives. For the current study, we analyzed twin data from ANTR surveys 7 and 8, which were collected between 2004 and 2005 (survey 7), and between 2009 and 2011 (survey 8). The adult twins were on average 29.77 years old (SD: 12.5 ). The Conners' Adult ADHD Rating Scales (CAARS), which we used to assess inattention and hyperactivity, was first introduced in ANTR survey 7 (Distel et al. 2007). However, this seventh survey did not include an assessment of aggression. ANTR survey 8 (Geels et al. 2013) was collected in two waves. Surveys from the first wave ( $83 \%$ of all responders) included the ASEBA-Adult Self Report aggression scale. The bottom part of Table 3 gives the total number of participants (total number of twin pairs is $7433 ; 46 \% \mathrm{MZ}$ ) and the number of missing values by twin member and phenotype. In contrast to the child data, the adult dataset had a substantial number of incomplete twin pairs (32\% for MZ pairs and 51\% for DZ pairs).

\section{Zygosity Assessment}

Most YNTR and ANTR surveys include a set of items concerning the twins' physical resemblance and the degree to which the twins, in childhood, were confused by parents, other relatives, and strangers. In the YNTR and ANTR data, discriminant analyses were performed to assess the accuracy of zygosity classification based on survey items, using information from blood group and DNA polymorphisms as the index of true zygosity (Ligthart et al. 2019). In both the YNTR and ANTR, the accuracy of classification was high, ranging between 92 and $96 \%$, depending on age and rater. In $31 \%$ of same-sex young twins and in the majority of samesex ANTR twins (59\%) zygosity assessment was based on DNA information.

\section{YNTR Phenotyping}

The Child Behavior Checklist (CBCL) is a standardized questionnaire designed for parents to report the frequency and intensity of their children's behavioral and emotional problems (Achenbach et al. 2017). It is part of the Achenbach System of Empirically Based Assessment (ASEBA: https://aseba.org/), and consists of 120 items, which are rated on a 3-point scale. The response options range from "not true $=0$ ", "somewhat or sometimes true $=1$ ", to "very true or often true $=2$ "'. The Aggression Problem subscale contains 18 items; the total aggression score ranges from 0 to 36 , allowing for up to 3 missing items (van Beijsterveldt et al. 2003). The Conners' Parent Rating Scale-Revised (CPRS-R; Conners 2001; Conners et al. 1998; Derks et al. 2008) also assesses behavioral problems in children by parental ratings. The short version contains 27 items, which are rated on a 4-point scale, ranging from " not true at all $=0$ " to "very much true $=3$ ". The two CPRS-R subscales that measure hyperactivity and inattention consist of 6 items each, allowing for 1 missing item per subscale. The phenotypic scores range from 0 to 18 . The CPRS-R has good internal and test-retest reliability (Faries et al. 2001).

\section{ANTR Phenotyping}

The adult twins completed the ASEBA Adult Self Report (ASR) (Achenbach et al. 2017), which includes 15 aggression items that are rated on a 3-point scale, allowing for 3 missing items. The resulting aggression scores range from 0 to 30 (Hagenbeek et al. 2018). The Conners' Adult ADHD Rating Scales screening self-report (CAARS-S:SV) includes two 9-item subscales for the quantitative assessment of inattentive symptoms (inattention) and hyperactiveimpulsive symptoms (hyperactivity). There are no items common to the subscales. The items in the inattention and hyperactivity scales correspond to the symptoms that represent the diagnostic criteria of adult ADHD as outlined in DSM-IV-TR. All items were scored on a scale from "not true at all $=0$ " to "very much true $=3$ ". The sum score of each subscale ranged from 0 to 27. Missing items were handled as per CAARS instructions (Conners et al. 1999; Saviouk et al. 2011) which allows the scoring of scales with up to two missing items.

\section{Statistical Analyses}

Statistical analyses were carried out in OpenMx (Neale et al. 2016) using full information maximum likelihood (ML) estimation. In all models, sex and age were included as fixed effects (the OpenMx scripts are given in the Online Appendix). 


\section{Phenotypic Regression of Aggression on Hyperactivity and Inattention}

We first carried out the phenotypic analyses, in which we regressed aggression (Agg) on sex, age, hyperactivity (HA) and inattention $(\operatorname{InA})$, in the child and in the adult cohort. The within-person regression model, depicted in Fig. 1 (where the fixed effects of sex and age are left out), is:

$$
\begin{aligned}
\operatorname{Agg}_{\mathrm{i}}= & \mathrm{b}_{0}+\mathrm{b}_{\mathrm{Sex}} * \mathrm{Sex}_{\mathrm{i}}+\mathrm{b}_{\mathrm{Age}} * \mathrm{Age}_{\mathrm{i}} \\
& +\mathrm{b}_{\mathrm{HA}} * \mathrm{HA}_{\mathrm{i}}+\mathrm{b}_{\mathrm{InA}} * \operatorname{InA}_{\mathrm{i}}+\varepsilon_{i},
\end{aligned}
$$

where the subscript $\mathrm{i}$ denotes person, and $\varepsilon$ is the prediction error (regression residual). Conditional on sex and age, the phenotypic aggression variance $\left(\mathrm{s}_{\text {Agg|age,sex }}^{2}\right)$ was decomposed into four parts:

$\mathrm{s}_{\mathrm{Agg} \text { lage }, \text { sex }}^{2}=\mathrm{b}_{\mathrm{HA}}^{2} * \mathrm{~s}_{\mathrm{HA}}^{2}+\mathrm{b}_{\mathrm{InA}}^{2} * \mathrm{~s}_{\mathrm{InA}}^{2}+2 * \mathrm{~b}_{\mathrm{HA}} * \mathrm{~b}_{\mathrm{InA}} * \mathrm{~s}_{\mathrm{HA}, \mathrm{InA}}+\mathrm{s}_{\varepsilon}^{2}$

The variance terms $b_{\mathrm{HA}}^{2} * \mathrm{~s}_{\mathrm{HA}}^{2}$ and $\mathrm{b}_{\mathrm{InA}}^{2} * \mathrm{~s}_{\mathrm{InA}}^{2}$ can be attributed to hyperactivity and inattention, respectively. However, the term $2 * \mathrm{~b}_{\mathrm{HA}} * \mathrm{~b}_{\mathrm{InA}} * \mathrm{~s}_{\mathrm{HA}, \text { InA }}$ which arises when HA and InA are correlated, cannot be attributed unambiguously to either. We therefore report these three variance components separately. We fitted the phenotypic regression models in OpenMx (Neale et al. 2016) to the all twin data, regardless of the patterns of missingness. In these analyses we constrained the regression to be equal over MZ and DZ groups and over twin 1 and twin 2 (the two twins in a pair) and left the MZ twin 1-MZ twin 2 covariances and the DZ twin 1-DZ twin 2 covariances unconstrained, to accommodate the dependence of the MZ and DZ twin data (Neale et al. 1994). Below, we report the standardized regression

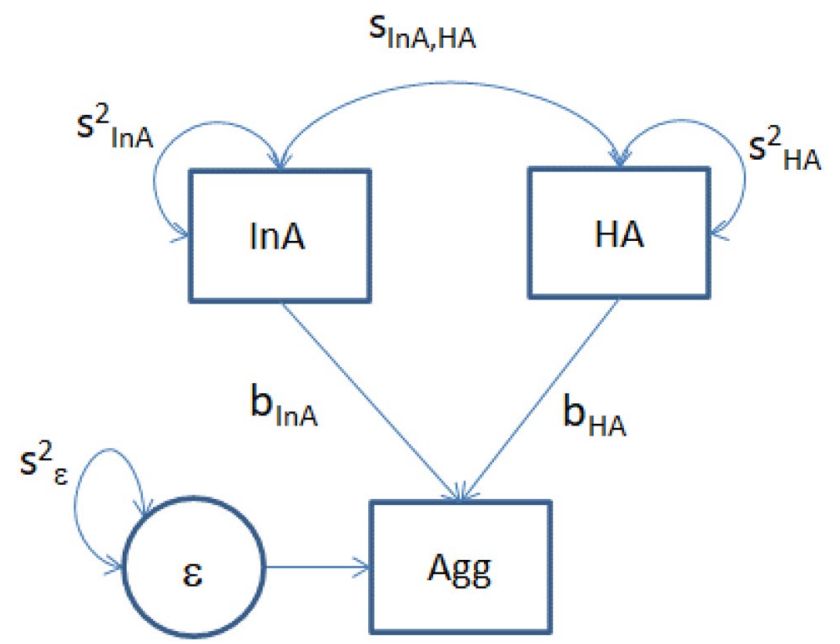

Fig. 1 Regression of aggression (Agg) on the correlated variables inattention (InA) and hyperactivity (HA). The covariates sex and age are not depicted coefficients, and the decomposition of the standardized variance of aggression.

\section{Genetic Modeling: ADCE Twin Model}

We first calculated the MZ and DZ $6 \times 6$ phenotypic covariance matrices, whose standardized solution is given to describe $\mathrm{MZ}$ and DZ twin resemblances and fitted a trivariate Cholesky decomposition to the data (Brezinski 2005) to estimate genetic and environmental covariance matrices for aggression, hyperactivity and inattention. The phenotypic $(3 \times 3)$ covariance matrix of the phenotypes, conditional on age and sex $\left(\sum_{\mathbf{p h} \mid \mathbf{a g e s s e x}}\right)$ was decomposed into the following four covariance matrices (Martin and Eaves 1977; Franić et al. 2012):

In the 10 year olds : $\sum_{\text {ph|age,sex }}=\sum_{\mathbf{A}}+\sum_{\mathbf{C}}+\sum_{\mathbf{D}}+\sum_{\mathbf{E}}$,

and in the adults : $\sum_{\text {ph|age,sex }}=\sum_{\mathbf{A}}+\sum_{\mathbf{D}}+\sum_{\mathbf{E}}$,

where $\Sigma_{\mathbf{A}}$ is the additive genetic covariance matrix, $\Sigma_{\mathbf{D}}$ the dominance genetic covariance matrix, $\Sigma_{\mathbf{C}}$ the common (shared between twins) environmental covariance matrix, and $\Sigma_{\mathbf{E}}$ the unique (unshared) environmental covariance matrix. To render the model identified in the 10-year olds, we added identifying constraints (informed by the $\mathrm{MZ}$ and DZ twin phenotypic correlations; see Tables 2 and 3). The $3 \times 3$ covariance matrix $\Sigma_{\mathbf{C}}$, which was included to accommodate the contribution of shared environmental influences to aggression, was specified as follows:

$\Sigma_{\mathrm{C}}=\Lambda_{\mathrm{C}} \Lambda_{\mathrm{C}}^{\mathrm{t}}$,

where $\mathbf{t}$ denotes transpose and $\boldsymbol{\Lambda}_{\mathbf{C}}$

$$
\Lambda_{C}=\begin{array}{cccc}
\text { Agg } & H A & \text { InA } \\
\text { Agg } & c_{11} & 0 & 0 \\
H A & c_{21} & 0 & 0 \\
\text { InA } & c_{31} & 0 & 0
\end{array}
$$

The parameter $c_{11}$ expresses the common environmental influences on aggression. We included the parameters $c_{21}$ and $c_{31}$ to accommodate shared environmental effects, if any, that are common to all three phenotypes. The $3 \times 3$ covariance matrix $\Sigma_{\mathbf{D}}$ was modeled as $\boldsymbol{\Lambda}_{\mathbf{D}} \boldsymbol{\Lambda}_{\mathbf{D}}{ }^{\mathrm{t}}$, where

$$
\boldsymbol{\Lambda}_{\mathbf{D}}=\begin{array}{cccc}
\text { Agg } & H A & \text { InA } \\
A g g & 0 & 0 & 0 \\
H A & 0 & d_{22} & 0 \\
\operatorname{InA} & 0 & d_{32} & d_{33}
\end{array}
$$


This is the Cholesky decomposition, with the dominance effects limited to hyperactivity and inattention. In both groups (children and adults), we modeled the additive genetic $3 \times 3$ covariance matrix $\Sigma_{\mathbf{A}}$ and the unshared environmental covariance matrix $\Sigma_{\mathbf{E}}$ as $\boldsymbol{\Lambda}_{\mathbf{A}} \boldsymbol{\Lambda}_{\mathbf{A}}{ }^{\mathrm{t}}$ and $\boldsymbol{\Lambda}_{\mathbf{E}} \boldsymbol{\Lambda}_{\mathbf{E}}{ }^{\mathrm{t}}$, respectively, where

$$
\begin{aligned}
& \text { Agg HA InA } \\
& \boldsymbol{\Lambda}_{\mathbf{A}}=\begin{array}{cccc}
A g g & a_{11} & 0 & 0 \\
H A & a_{21} & a_{22} & 0
\end{array} \\
& \begin{array}{llll}
\text { InA } & a_{31} & a_{32} & a_{33}
\end{array} \\
& \boldsymbol{\Lambda}_{\mathbf{E}}=\begin{array}{cccc}
A g g & H A & \text { InA } \\
H A & e_{11} & 0 & 0 \\
\operatorname{InA} & e_{21} & e_{22} & 0 \\
e_{32} & e_{33}
\end{array}
\end{aligned}
$$

That is, $\boldsymbol{\Lambda}_{\mathbf{A}}$ and $\boldsymbol{\Lambda}_{\mathbf{E}}$ were obtained from the full $3 \times 3$ Cholesky decomposition. The parameters were estimated by modeling the MZ and DZ twin covariance matrices $(6 \times 6: 3$ traits in two twins), conditional on age and sex:

MZ twin 1 MZ twin 2

MZ twin $1 \Sigma_{\mathrm{A}}+\Sigma_{\mathrm{C}}+\Sigma_{\mathrm{D}}+\Sigma_{\mathrm{E}} \Sigma_{\mathrm{A}}+\Sigma_{\mathrm{C}}+\Sigma_{\mathrm{D}}$ $\mathrm{MZ}$ twin $2 \Sigma_{\mathrm{A}}+\Sigma_{\mathrm{C}}+\Sigma_{\mathrm{D}} \quad \Sigma_{\mathrm{A}}+\Sigma_{\mathrm{C}}+\Sigma_{\mathrm{D}}+\Sigma_{\mathrm{E}}$

$$
\text { DZ twin } 1 \quad \text { DZ twin } 2
$$

DZ twin $1 \Sigma_{\mathrm{A}}+\Sigma_{\mathrm{C}}+\Sigma_{\mathrm{D}}+\Sigma_{\mathrm{E}} \quad .5 * \Sigma_{\mathrm{A}}+\Sigma_{\mathrm{C}}+.25 * \Sigma_{\mathrm{D}}$ DZ twin $2.5 * \Sigma_{\mathrm{A}}+\Sigma_{\mathrm{C}}+.25 * \Sigma_{\mathrm{D}} \Sigma_{\mathrm{A}}+\Sigma_{\mathrm{C}}+\Sigma_{\mathrm{D}}+\Sigma_{\mathrm{E}}$

where $\Sigma_{A}, \Sigma_{C}, \Sigma_{D}$ and $\Sigma_{E}$, are defined as above. We calculated the total genetic covariance matrix $\Sigma_{G}=\Sigma_{A}+\Sigma_{D}$ and the total environmental covariance matrix $\Sigma_{T}=\Sigma_{C}+\Sigma_{E}$ (in the adults, this is $\Sigma_{T}=\Sigma_{E}$ ).

\section{Genetic Modeling: A+D, C +E Regression Models}

The trivariate genetic modeling provided an insight into the genetic and non-genetic correlations of hyperactivity and inattention with aggression, but did not address explicitly the question which of the subscales HA and InA is the stronger predictor of aggression. We included the regression of aggression on hyperactivity and inattention at the level of the genetic $\Sigma_{\mathrm{G}}$ and the environmental covariance matrix $\Sigma_{\mathrm{T}}$, where $\Sigma_{\mathrm{G}}$ equals $\Sigma_{A}+\Sigma_{D}$, and $\Sigma_{\mathrm{T}}$ equals $\Sigma_{C}+\Sigma_{E}$. In the adults, we have $\Sigma_{T}=\Sigma_{E}$. We did not attempt to conduct the regression analysis at the level of the individual (A,D, C and E) covariance matrices because $\Sigma_{C}$ and $\Sigma_{D}$ are positive semidefinite by definition (i.e., rank 1 and rank 2 , respectively). In addition, $\Sigma_{\mathrm{A}}$ was found to be positive semi-definite (rank

\begin{tabular}{|c|c|c|c|}
\hline & Agg & $H A$ & $\operatorname{In} A$ \\
\hline \multirow{3}{*}{$\Sigma_{\mathrm{G}}=$} & $\mathrm{S}_{\mathrm{G}^{2}}{ }_{\mathrm{A}} \mathrm{Agg}$ & $\mathrm{S}_{G_{-}} \mathrm{HA}, \mathrm{Agg}$ & $\mathrm{S}_{\mathrm{G} \_\ln \mathrm{A}, \mathrm{Agg}}$ \\
\hline & $\mathrm{S}_{G_{-} H A, A g g}$ & $\mathrm{SG}^{2}{ }^{2} \mathrm{~A}$ & $\mathrm{~S}_{\mathrm{G}_{-} \mathrm{In} \mathrm{A}, \mathrm{HA}}$ \\
\hline & $S_{G} \_\ln A, A g g$ & $\mathrm{~S}_{\mathrm{G}_{-} \operatorname{In} \mathrm{A}, \mathrm{HA}}$ & $\mathrm{SG}^{2} \operatorname{In} \mathrm{A}$, \\
\hline
\end{tabular}
1) in the children. We therefore defined covariance matrices $\Sigma_{\mathrm{G}}$ and $\Sigma_{\mathrm{T}}$ to conduct the regression analyses at the total genetic $(\mathrm{G})$ and the total (T) environmental level. Specifically, given $\Sigma_{\mathrm{G}}\left(\right.$ i.e., $\left.\Sigma_{A}+\Sigma_{D}\right)$,

we partitioned the matrix into the following matrices:

$$
\begin{aligned}
& H A \quad \operatorname{InA} \\
& \Sigma_{\mathbf{G} 2}=H A \quad \mathrm{~S}_{\mathrm{G}}{ }^{2} \mathrm{HA} \quad \mathrm{S}_{\mathrm{G}_{-} \ln \mathrm{H}, \mathrm{HA}} \\
& \operatorname{In} A \quad \mathrm{SG}_{-} \operatorname{In} \mathrm{A}, \mathrm{HA} \quad \mathrm{SG}^{2} \operatorname{In} \mathrm{A} \text {, }
\end{aligned}
$$

i.e., the genetic covariance matrix of hyperactivity and inattention, and

$$
\begin{aligned}
& \text { Agg } \\
& \Sigma_{\mathbf{G} 1}=H A \quad \mathrm{~S}_{G_{-}} \mathrm{HA}, \mathrm{Agg} \\
& \text { In } A \quad \mathrm{~S}_{\mathrm{G}} \text { InA,Agg, }
\end{aligned}
$$

i.e., the genetic covariance of aggression with hyperactivity and inattention. We calculated the genetic regression coefficients $\mathbf{b}_{\mathrm{G}}=\left[\mathrm{b}_{\mathrm{G} \_\mathrm{HA}}, \mathrm{b}_{\mathrm{G} \_ \text {InA }}\right]^{\mathrm{t}}$ as follows: $\mathbf{b}_{\mathrm{G}}=\Sigma_{\mathrm{G} 2}^{-1} \Sigma_{\mathrm{G} 1}$. The decomposition of genetic variance associated with the genetic regression model is:

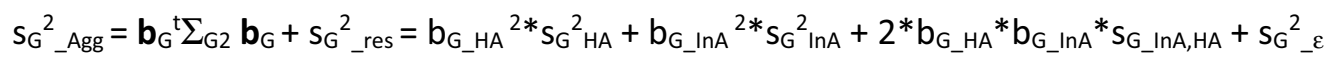


Table 1 Variance components based on regression analysis with aggression as outcome and hyperactivity and inattention as predictors: variance components due to hyperactivity, inattention, the covar- iance of hyperactivity and inattention (unassigned to either hyperactivity or inattention) and a residual term

\begin{tabular}{|c|c|c|c|}
\hline Hyperactivity (HA) & Inattention $(\ln A)$ & Unassigned & Residu \\
\hline $\mathrm{b}_{\mathrm{HA}}{ }^{2 *} \mathrm{~s}^{2}{ }_{\mathrm{HA}} / \mathrm{s}^{2}{ }_{\mathrm{Agg}}$ & $\mathrm{b}_{\operatorname{lnA}}{ }^{2 *} \mathrm{~s}^{2} \ln \mathrm{A} / \mathrm{s}^{2} \mathrm{Agg}$ & $2 * b_{H A} * b_{\operatorname{lnA}} * s_{\mathrm{HA}, \operatorname{lnA}} / \mathrm{s}^{2}{ }_{\mathrm{Agg}}$ & $\mathrm{S}^{2}{ }_{\varepsilon} / \mathrm{s}^{2} \mathrm{Agg}$ \\
\hline
\end{tabular}

Genetic variance components standardized by genetic variance $S_{G}{ }^{2} A g g$

Hyperactivity (HA) Inattention (InA) Unassigned

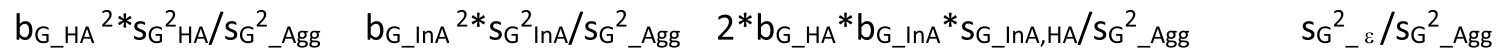

Environmental variance components standardized by total environmental variance $S_{T}^{2} \mathrm{Agg}$

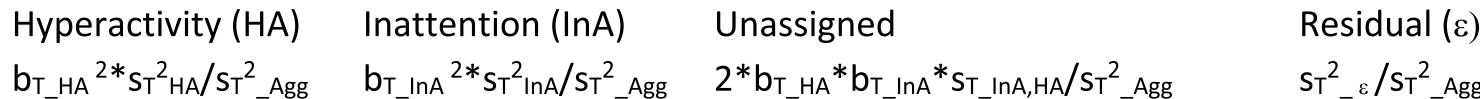

Genetic and environmental variance components standardized by phenotypic variance $s^{2}$ Agg

\begin{tabular}{|c|c|c|c|}
\hline Hyperactivity (HA) & Inattention $(\ln A)$ & Unassigned & Residual $(\varepsilon)$ \\
\hline & gg & $2 * b_{G_{B} H A} * b_{G_{I} I n A} * s_{G_{I} \ln }$ & $\mathrm{SG}^{2}$ \\
\hline${ }_{H A}{ }^{2 *} \mathrm{ST}^{2} \mathrm{HA} / \mathrm{S}^{2}{ }_{-} \mathrm{Ag}$ & $\mathrm{b}_{\mathrm{T} \_\operatorname{InA}}{ }^{2 *} \mathrm{ST}^{2} \ln \mathrm{A} / \mathrm{s}^{2}{ }_{-} \mathrm{Agg}$ & $2 * b_{T_{-} H A} * b_{T \_I n A} * S_{T \_I n A, H A} / s^{2}{ }_{-A g g}$ & \\
\hline
\end{tabular}

$b=$ regression coefficient, $s^{2}=$ total phenotypic variance, $s_{\mathrm{G}}{ }^{2}=\left(\right.$ broad-sense) genetic variance, $s_{T}{ }^{2}=$ total environmental variance

where $\mathrm{s}_{\mathrm{G}}{ }^{2}{ }_{\varepsilon}$ is the genetic prediction error variance. Using the same approach, we calculated $\mathbf{b}_{\mathrm{T}}=\left[\mathrm{b}_{\mathrm{T} \_\mathrm{HA}}, \mathrm{b}_{\mathrm{T} \_ \text {InA }}\right]^{\mathrm{t}}$ as follows $\mathbf{b}_{\mathrm{T}}=\Sigma_{\mathrm{T} 2}^{-1} \Sigma_{\mathrm{T} 1}$, and obtained the decomposition of total environmental variance: values in the child and in the adult sample. In the children (Table 2), the phenotypic correlations among the three traits revealed that the correlation of Agg with HA $(\sim 0.60)$ is higher than the correlation of Agg with InA ( 0.45), while

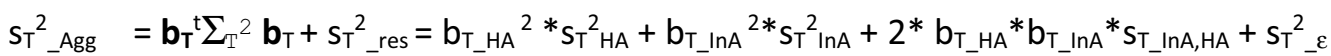

Given estimates of the phenotypic, genetic, and environmental variance components, we standardized these by dividing by the total phenotypic, genetic, and environmental variance. The results of main interest are the genetic and environmental variance components standardized by the total phenotypic variance, as these reveal the relative contributions of genetic and environmental factors to the phenotypic regression of aggression on hyperactivity and inattention. Table 1 contains a summary of the decompositions of variance in the regression models.

\section{Results}

\section{Descriptive Statistics and Phenotypic Regression Analysis}

Tables 2 and 3 contain the MZ and DZ correlation matrices, standard deviations, sample sizes and the number of missing the correlation between the two predictors InA and HA is $\sim 0.61$. In the adults (Table 3 ), we note that the correlations are appreciable lower. The correlations of Agg with HA are between 0.29 and $\sim 0.36$ and the correlations of Agg with InA are consistently greater, between $\sim 0.35$ and $\sim 0.48$. The correlation between the predictors InA and HA varies between $\sim 0.40$ and $\sim 0.46$. Based on these results, it would seem that in the children HA may be the stronger predictor of Agg, while in the adults, InA is the stronger predictor. However, it is important to note that in adults hyperactivity and inattention were assessed four years before aggression was measured, which may have influenced the results.

We conducted phenotypic regression analyses on the basis of the within person phenotypic covariance (AggInA-HA) matrices. Results for these phenotypic analyses are summarized in Table 4A, which includes the standardized variance decomposition conditional on age and sex. Based on these results, Table 4B presents the proportions 
Table 2 Children (10-year olds)

\begin{tabular}{|c|c|c|c|c|c|c|c|c|}
\hline & Agg1 & InA1 & HA1 & & Agg2 & & InA2 & HA2 \\
\hline \multicolumn{9}{|l|}{ MZ } \\
\hline Agg1 & 1.000 & & & & & & & \\
\hline InA1 & 0.456 & 1.000 & & & & & & \\
\hline HA1 & 0.605 & 0.611 & 1.000 & & & & & \\
\hline Agg2 & 0.797 & 0.381 & 0.504 & & 1.000 & & & \\
\hline InA2 & 0.385 & 0.722 & 0.483 & & 0.443 & & 1.000 & \\
\hline HA2 & 0.518 & 0.497 & 0.772 & & 0.587 & & 0.620 & 1.000 \\
\hline SD & 4.772 & 3.798 & 2.905 & & 4.601 & & 3.829 & 2.934 \\
\hline \multicolumn{9}{|l|}{$\mathrm{DZ}$} \\
\hline Agg1 & 1.000 & & & & & & & \\
\hline InA1 & 0.454 & 1.000 & & & & & & \\
\hline HA1 & 0.587 & 0.615 & 1.000 & & & & & \\
\hline Agg2 & 0.442 & 0.230 & 0.271 & & 1.000 & & & \\
\hline $\operatorname{In} \mathrm{A} 2$ & 0.232 & 0.186 & 0.227 & & 0.439 & & 1.000 & \\
\hline HA2 & 0.254 & 0.208 & 0.276 & & 0.582 & & 0.620 & 1.000 \\
\hline \multirow[t]{3}{*}{ SD } & 4.865 & 4.065 & 3.081 & & 4.682 & & 4.072 & 3.204 \\
\hline & & \multicolumn{7}{|c|}{ Missing values (individuals) for twin 1 and twin 2} \\
\hline & & Agg 1 & InA1 & HA1 & & $\operatorname{Agg} 2$ & InA2 & HA2 \\
\hline \multicolumn{9}{|c|}{ Total sample size (number of pairs) and marginal number of missing* values } \\
\hline MZ & 4209 & 33 & 1125 & 1115 & & 65 & 1120 & 1113 \\
\hline $\mathrm{DZ}$ & 7136 & 33 & 1703 & 1696 & & 100 & 1727 & 1712 \\
\hline
\end{tabular}

MZ and DZ correlation matrices of within-person, twin correlations (in bold) and cross-twin cross-trait correlations and standard deviations (corrected for sex and age) for Aggression (Agg), Inattention (InA) and hyperactivity (HA) in twin 1 and twin 2

$S D$ standard deviation

*In the earlier birth cohorts data on InA and HA were not collected

of explained phenotypic variance in aggression by the main effects of InA and HA, and by their covariance.

We first discuss the results in the children, where we note a consistent effect of sex. On average, girls scored lower than boys on all three phenotypes. The effects of age on Agg and InA were not significant (judging by the standard errors), but there was an effect of age on HA $(\alpha=0.05)$. Even in this sample with limited variation in age (average age: 9.94 years; SD: 0.51), HA decreased with age, indicating fewer HA problems as children grow up $\left(\mathrm{b}_{\mathrm{Age}}=-0.235\right.$, se $\left.=0.057\right)$. Overall, sex and age combined explained about 1.9\%, 3.6\%, and $4.4 \%$ of the phenotypic variance of Agg, InA, and HA, respectively. Conditional on sex and age, we obtained regression coefficients of 0.165 (CI-95: 0.154-0.184 for InA) and 0.773 (CI-95: 0.758-0.798 for HA) in the regression of Agg on InA and HA. The total explained variance was $35.6 \%$ : InA explained 1.9\% (CI-95: 1.6-2.4\%) and HA explained 25.2\% (CI-95: 23.6-26.7\%) of the phenotypic Agg variance. The component due to the covariance between InA and HA explained an additional 8.5\% (CI-95: 7.8-9.4\%). Clearly HA emerged as the better phenotypic predictor, accounting for
$25.2 \% / 35.6 \%=\sim 71 \%$ of the explained variance, with InA accounting for $1.9 \% / 35.6 \%=\sim 5 \%$ and the covariance of $\operatorname{InA}$ and HA accounting for $8.5 \% / 35.6 \%=\sim 24 \%$ of the explained variance.

In the adults, we note a significant effect of sex on Agg and InA $(\alpha=0.05)$, but no sex effect on HA. On average females scored higher on Agg and lower on InA. The effect of age was consistently negative, indicating lower scores with increasing age. Overall, sex and age combined explained $2.8 \%, 1.4 \%$, and $0.1 \%$ of the phenotypic variance of Agg, InA, and HA, respectively. Conditional on sex and age, we obtained regression coefficients of 0.293 (CI-95: 0.273-0.300; InA) and 0.173 (CI-95: 0.138-0.174; $\mathrm{HA}$ ) in the regression of Agg on InA and HA. The total explained variance was $18.6 \%$ : InA explained $10.6 \%$ (CI95: $9.3-10.7 \%$ ) and HA explained 3.1\% (CI-95: $1.9-3.1 \%$ ) of the phenotypic Agg variance. The component due to the covariance between InA and HA explained an additional $4.9 \%$ (CI-95: $4.4-5.1 \%$ ). These results suggest that InA is the better phenotypic predictor in the adults, accounting to $10.6 \% / 18.6 \%=57 \%$ of the explained variance with HA and 
Table 3 Adults

\begin{tabular}{|c|c|c|c|c|c|c|c|c|}
\hline & Agg1 & InA1 & HA1 & & Agg2 & & InA2 & HA2 \\
\hline \multicolumn{9}{|l|}{$\mathrm{MZ}$} \\
\hline Agg1 & 1.000 & & & & & & & \\
\hline InA1 & 0.348 & 1.000 & & & & & & \\
\hline HA1 & 0.310 & 0.421 & 1.000 & & & & & \\
\hline Agg2 & 0.460 & 0.224 & 0.199 & & 1.000 & & & \\
\hline InA2 & 0.227 & 0.425 & 0.160 & & 0.391 & & 1.000 & \\
\hline HA2 & 0.173 & 0.220 & 0.365 & & 0.290 & & 0.460 & 1.000 \\
\hline SD & 3.338 & 3.568 & 3.474 & & 3.265 & & 3.683 & 3.405 \\
\hline \multicolumn{9}{|l|}{ DZ } \\
\hline Agg1 & 1.000 & & & & & & & \\
\hline InA1 & 0.479 & 1.000 & & & & & & \\
\hline HA1 & 0.360 & 0.440 & 1.000 & & & & & \\
\hline Agg2 & 0.172 & 0.189 & 0.010 & & 1.000 & & & \\
\hline $\operatorname{In} \mathrm{A} 2$ & 0.053 & 0.203 & 0.089 & & 0.406 & & 1.000 & \\
\hline HA2 & -0.010 & 0.138 & 0.128 & & 0.319 & & 0.395 & 1.000 \\
\hline \multirow[t]{3}{*}{ SD } & 3.373 & 3.861 & 3.559 & & 3.443 & & 3.746 & 3.317 \\
\hline & & \multicolumn{7}{|c|}{ Missing values (individuals) for twin 1 and twin 2} \\
\hline & & Agg1 & InA1 & HA1 & & Agg2 & InA2 & HA2 \\
\hline \multicolumn{9}{|c|}{ Total sample size (number of pairs) and marginal number of missing* values } \\
\hline MZ & 3438 & 1689 & 1351 & 1350 & & 1689 & 1462 & 1689 \\
\hline $\mathrm{DZ}$ & 3995 & 2284 & 1976 & 1973 & & 2332 & 2166 & 2332 \\
\hline
\end{tabular}

$\mathrm{MZ}$ and DZ correlation matrices of within-person, twin correlations (in bold) and cross-twin cross-trait correlations and standard deviations (corrected for sex and age) for Aggression (Agg), Inattention (InA) and hyperactivity (HA) in twin 1 and twin 2

$S D$ standard deviation

*Data collection for InA and HA preceded data collection for Aggression by 4 years; for InA and HA data collection took place in ANTR survey 7, for Aggression in ANTR survey 8

the covariance of HA accounting for $3.1 \% / 18.6 \%=17 \%$ and $4.9 \% / 18.6 \%=26 \%$, respectively. However, the 4-year interval between the assessment of Agg and ADHD should be considered when interpreting these results.

\section{Combined Genetic Covariance Structure and Regression Analyses in 10-Year Olds}

Table 2 presents the correlations between twins and among scales in children. The MZ twin correlations were 0.79 (Agg), 0.72 (InA), and 0.77 (HA). The DZ correlations were substantially lower: 0.44 (Agg), 0.18 (InA), and 0.27 (HA). In the genetic covariance structure model, we therefore included additive genetic (A), dominance genetic (D), common environmental $(\mathrm{C})$ and unique environmental (E) components (see model specification of matrices above). Based on twin data from mono- and dizygotic twins the full ADCE model is not identified and constraints as outlined above were applied to the $3 \times 3 \mathrm{C}$ and D matrices. The estimates obtained in fitting the ADCE model are given in Table 5.
Heritability of Agg was $71 \%$ and common environment shared by twins accounted for $8 \%$ of the phenotype Agg variance. The estimates for the total heritability of HA and InA were also high, with relatively large contributions of genetic dominance. The broad-sense heritability of HA was $17 \%(\mathrm{~A})+55 \%(\mathrm{D})=72 \%$ and of $\operatorname{InA} 38 \%+46 \%=74 \%$. Common environmental influences (shared with aggression) accounted for $1.4 \%$ and $1.1 \%$ of the variance of HA and InA, respectively. The $\mathrm{C}$ variance-covariance matrix is rank 1, which follows from our model specifications by definition, and matrix $\mathrm{D}$ is rank 2, again by definition. We found that matrix $\mathrm{A}$ is almost rank 1 (eigenvalues $=21.99$, $0.006, \sim 0.00$ ) and matrix $\mathrm{E}$ is rank 3 . As mentioned above, given the ranks of these matrices, it is not possible to assess the regression model at the level of A, D and $\mathrm{C}$ (the covariance matrices of the predictors are singular). We therefore based the regression analyses on total genetic effects (broad sense: $G=A+D$ ) and the total environmental effects $(\mathrm{T}=\mathrm{C}+\mathrm{E})$. The $\mathrm{A}+\mathrm{D}$ and $\mathrm{C}+\mathrm{E}$ matrices both have rank 3 . The estimates of the regression coefficients, for 
Table 4 Phenotypic regression results in children and adults, with Aggression (Agg) as outcome and Inattention (InA) and Hyperactivity (HA) as predictors, where: $\operatorname{Agg}_{\mathrm{i}}=\mathrm{b}_{0}+\mathrm{b}_{\mathrm{Sex}} * \operatorname{Sex}_{\mathrm{i}}+\mathrm{b}_{\mathrm{Age}} * \mathrm{Age}_{\mathrm{i}}+\mathrm{b}_{\mathrm{InA}} * \operatorname{InA}_{\mathrm{i}}+\mathrm{b}_{\mathrm{HA}} * \mathrm{HA}_{\mathrm{i}}+\varepsilon_{\mathrm{i}}$,

\begin{tabular}{|c|c|c|c|}
\hline & Agg & $\operatorname{In} A$ & HA \\
\hline \multicolumn{4}{|l|}{ Children } \\
\hline Intercept $\left(\mathbf{b}_{0}\right)$ & 0.044 (se 0.890$)$ & $5.23($ se 0.700$)$ & $5.38($ se 0.567$)$ \\
\hline $\operatorname{Sex}\left(\mathbf{b}_{\text {Sex }}\right)$ & $-1.18(\mathrm{se} 0.063)$ & $-1.47(\mathrm{se} 0.063)$ & $-1.33(\mathrm{se} 0.047)$ \\
\hline Age $\left(\mathbf{b}_{\text {Age }}\right)$ & 0.050 (se 0.089) & $-0.086($ se 0.070$)$ & $-0.235($ se 0.057$)$ \\
\hline Phenotypic Agg on InA ( $\left.\mathbf{b}_{\text {InA }}\right)$ & $0.165(0.154-0.184)$ & & \\
\hline Phenotypic Agg on HA $\left(\mathbf{b}_{\mathbf{H A}}\right)$ & $0.773(0.758-0.798)$ & & \\
\hline \multicolumn{4}{|l|}{ Adults } \\
\hline Intercept $\left(\mathbf{b}_{0}\right)$ & $3.86($ se 0.126$)$ & 7.57 (se.134) & 7.58 (se 0.123) \\
\hline $\operatorname{Sex}\left(\mathbf{b}_{\text {Sex }}\right)$ & 0.727 (se 0.089 ) & $-0.244($ se.093) & 0.050 (se 0.086$)$ \\
\hline Age $\left(\mathbf{b}_{\text {Age }}\right)$ & $-0.036($ se 0.003$)$ & -0.035 (se .003$)$ & $-0.010($ se 0.003$)$ \\
\hline Phenotypic Agg on InA $\left(\mathbf{b}_{\text {InA }}\right)$ & $0.293(0.273-0.300)$ & & \\
\hline Phenotypic Agg on HA $\left(\mathbf{b}_{\mathbf{H A}}\right)$ & $0.173(0.138-0.174)$ & & \\
\hline \multicolumn{4}{|c|}{ B. Proportions of explained phenotypic variance of Agg with CI-95 intervals in parentheses } \\
\hline & $\mathrm{b}_{\text {InA }}{ }^{2 *} \mathrm{~s}^{2}{ }_{\text {InA }} / \mathrm{s}^{2}{ }_{\mathrm{Agg}}$ & $\mathrm{b}_{\mathrm{HA}}{ }^{2 *} \mathrm{~s}_{\mathrm{HA}}^{2} / \mathrm{s}^{2}{ }_{\mathrm{Agg}}$ & $2 * \mathrm{~b}_{\mathrm{HA}} * \mathrm{~b}_{\mathrm{InA}} * \mathrm{~s}_{\mathrm{HA}, \mathrm{InA}} / \mathrm{s}^{2}{ }_{\mathrm{Agg}}$ \\
\hline Kids: Proportion of variance & $0.019(0.016-0.024)$ & $0.252(0.236-0.267)$ & $0.085(0.078-0.094)$ \\
\hline Adults: Proportion of variance & $0.106(0.093-0.107)$ & $0.031(0.019-0.031)$ & $0.049(0.044-0.051)$ \\
\hline
\end{tabular}

$\mathrm{s}^{2}$ stands for variance and $\mathrm{s}$ represents standard deviation; $\mathrm{s}_{\mathrm{HA}, \mathrm{InA}}$ is the covariance of InA and HA

Table 5 Estimates of additive and dominance genetic and common and unique environmental variance-covariance matrices $(\Sigma)$, based on fitting an ADCE model to the trivariate twin data, conditional on age and sex

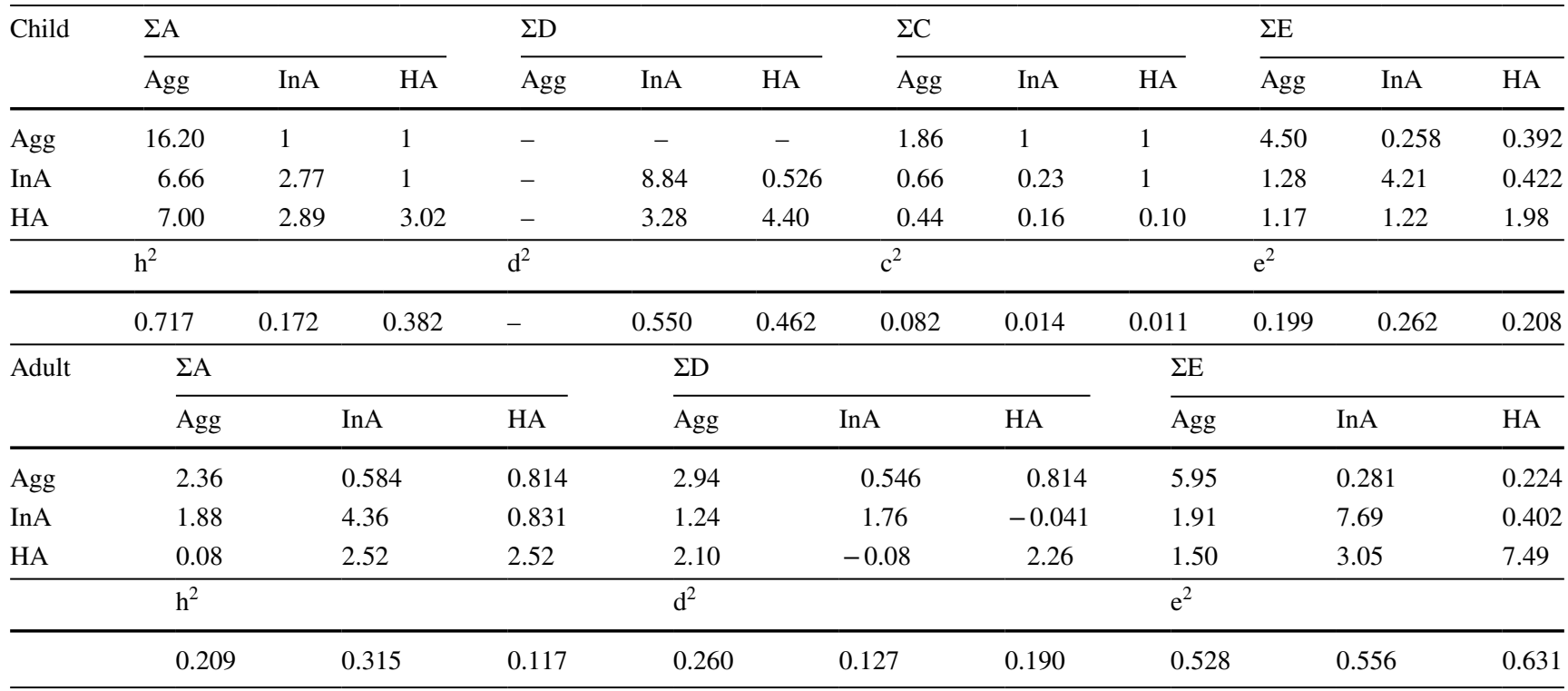

The lower triangles give (co)variances, and the upper triangle correlations. The last row (for children and for adults) contains the standardized variance components $\left(h^{2}\right.$ is heritability; $\mathrm{d}^{2}, \mathrm{c}^{2}$ and $\mathrm{e}^{2}$ give the proportions of variance explained by $\mathrm{D}, \mathrm{C}$ and $\mathrm{E}$ )

the phenotypic, genetic and non-genetic components in our model, are given in Table 6.

Effects of sex and age closely resembled the results as obtained in the phenotypic analysis (Table 4). The regression coefficients in the A+D part of the model were 0.134 for InA (CI-95: 0.091-0.174) and 0.830 for HA (CI =95: 0.778-0.881). In the $\mathrm{C}+\mathrm{E}$ part of the model these were 0.205 for InA (CI-95: 0.149-0.268) and 0.636 for HA 
Table 6 Genetic $(\mathrm{G}(\mathrm{A}+\mathrm{D}))$ and environmental $(\mathrm{T}(\mathrm{C}+\mathrm{E}))$ regression results in children, where for both the genetic and environmental regression $\mathrm{Agg}_{\mathrm{i}}=\mathrm{b}_{0}+\mathrm{b}_{\mathrm{Sex}} * \mathrm{Sex}_{\mathrm{i}}+\mathrm{b}_{\mathrm{Age}} * \mathrm{Age}_{\mathrm{i}}+\mathrm{b}_{\mathrm{InA}} * \operatorname{InA}_{\mathrm{i}}+\mathrm{b}_{\mathrm{HA}} * \mathrm{HA}_{\mathrm{i}}+\varepsilon_{\mathrm{i}}$

\begin{tabular}{|c|c|c|c|c|}
\hline \multicolumn{2}{|l|}{ Child } & Agg & InA & HA \\
\hline \multicolumn{5}{|c|}{ Raw regression coefficients with standard errors (se) or CI-95 intervals in parentheses } \\
\hline \multicolumn{2}{|l|}{ Intercept $\left(\mathbf{b}_{0}\right)$} & 0.047 (se 0.760$)$ & $5.28($ se 0.705$)$ & $5.39($ se 0.515$)$ \\
\hline \multicolumn{2}{|l|}{$\operatorname{Sex}\left(\mathbf{b}_{\text {sex }}\right)$} & $-1.18($ se 0.063$)$ & $-1.49(\mathrm{se} 0.063)$ & $-1.33($ se 0.047$)$ \\
\hline \multicolumn{2}{|l|}{ Age $\left(\mathbf{b}_{\text {Age }}\right)$} & $0.050($ se 0.076$)$ & $-0.090($ se 0.071$)$ & $-0.237($ se 0.052$)$ \\
\hline \multicolumn{2}{|c|}{$\mathrm{G}(\mathrm{A}+\mathrm{D}) \mathrm{Agg}$ on $\operatorname{InA}\left(\mathbf{b}_{\mathbf{I n A}}\right)$} & $0.134(0.091-0.174)$ & & \\
\hline \multicolumn{2}{|c|}{$\mathrm{G}(\mathrm{A}+\mathrm{D}) \mathrm{Agg}$ on $\mathrm{HA}\left(\mathbf{b}_{\mathbf{H A}}\right)$} & $0.830(0.778-0.881)$ & & \\
\hline \multicolumn{2}{|c|}{$\mathrm{T}(\mathrm{C}+\mathrm{E}) \operatorname{Agg}$ on $\operatorname{In} \mathrm{A}\left(\mathbf{b}_{\mathbf{I n A}}\right)$} & $0.205(0.149-0.268)$ & & \\
\hline \multicolumn{2}{|c|}{$\mathrm{T}(\mathrm{C}+\mathrm{E})$ Agg on HA $\left(\mathbf{b}_{\mathbf{H A}}\right)$} & $0.636(0.532-0.744)$ & & \\
\hline \multicolumn{5}{|c|}{ Proportions of explained phenotypic variance of Agg with CI-95 intervals in parentheses } \\
\hline \multirow{3}{*}{ Explained by $\mathrm{G}(\mathrm{A}+\mathrm{D})$} & Total genetic & $\mathrm{b}_{\mathrm{G} \_I n A}{ }^{2 *} \mathrm{~s}_{\mathrm{G}}{ }^{2}$ InA $/ \mathrm{s}_{\mathrm{G}}{ }^{2} \_\mathrm{Agg}$ & $\mathrm{b}_{\mathrm{G}_{-} \mathrm{HA}}{ }^{2} *_{\mathrm{s}_{\mathrm{G}}{ }^{2} \mathrm{AA}} / \mathrm{s}_{\mathrm{G}}{ }^{2} \mathrm{Agg}$ & $2 * \mathrm{~b}_{\mathrm{G} \_\mathrm{HA}} * \mathrm{~b}_{\mathrm{G} \_\mathrm{InA}} * \mathrm{~s}_{\mathrm{G} \_ \text {InA,HA }} / \mathrm{s}_{\mathrm{G}}{ }^{2} \_\mathrm{Agg}$ \\
\hline & 0.414 & $0.013(0.006-0.018)$ & $0.316(0.275-0.358)$ & $0.085(0.060-0.108)$ \\
\hline & Total environ. & $\mathrm{b}_{\mathrm{T} \_ \text {InA }}{ }^{2} *_{\mathrm{T}_{\mathrm{InA}}}^{2} / \mathrm{s}_{\mathrm{T}}^{2}{ }_{-\mathrm{Agg}}$ & $\mathrm{b}_{\mathrm{T}_{-} \mathrm{HA}}{ }^{2} *_{\mathrm{s}_{\mathrm{T}} \mathrm{HA}^{2}}^{2} / \mathrm{s}_{\mathrm{T} \_\mathrm{Agg}}^{2}$ & $2 * \mathrm{~b}_{\mathrm{T} \_\mathrm{HA}} * \mathrm{~b}_{\mathrm{T} \_ \text {InA }} * \mathrm{~s}_{\mathrm{T} \_\mathrm{InA}, \mathrm{HA}} / \mathrm{s}_{\mathrm{T}}{ }^{2}$ Agg \\
\hline \multirow[t]{2}{*}{ Explained by $\mathrm{T}(\mathrm{C}+\mathrm{E})$} & 0.219 & $0.029(0.014-0.031)$ & $0.133(0.130-0.190)$ & $0.056(0.036-0.080)$ \\
\hline & Total phenot. & $\mathrm{b}_{\mathrm{G}_{-} \mathrm{InA}}{ }^{2} \mathrm{~s}_{\mathrm{G}}{ }^{2} \operatorname{InA} / \mathrm{s}^{2}{ }_{\mathrm{Agg}}$ & $\mathrm{b}_{\mathrm{G} \_ \text {InA }}{ }^{2 *} \mathrm{~s}_{\mathrm{G}}{ }_{\text {InA }}^{2} / \mathrm{s}^{2}{ }_{\text {Agg }}$ & $2 * \mathrm{~b}_{\mathrm{G} \_\mathrm{HA}} * \mathrm{~b}_{\mathrm{G} \_\mathrm{InA}} * \mathrm{~s}_{\mathrm{G} \_ \text {InA,HA }} / \mathrm{s}^{2}{ }_{-\mathrm{Agg}}$ \\
\hline \multirow[t]{2}{*}{ Explained by $\mathrm{G}(\mathrm{A}+\mathrm{D})$} & 0.297 & $0.009(0.004-0.016)$ & $0.226(0.200-0.257)$ & $0.061(0.058-0.076)$ \\
\hline & & $\mathrm{b}_{\mathrm{T}_{-} \text {InA }}{ }^{2 *} \mathrm{~s}_{\mathrm{T}}{ }^{2} \operatorname{InA} \mathrm{s}^{2}{ }_{-} \mathrm{Agg}$ & $\mathrm{b}_{\mathrm{T}_{-} \mathrm{HA}}{ }^{2} *_{\mathrm{S}_{\mathrm{T}}{ }_{\mathrm{HA}}}^{2} / \mathrm{s}^{2}{ }_{-} \mathrm{Agg}$ & $2 * \mathrm{~b}_{\mathrm{T}_{-} \mathrm{HA}} * \mathrm{~b}_{\mathrm{T}_{-} \mathrm{InA}}{ }^{* \mathrm{~s}_{\mathrm{T} \_\mathrm{InA}, \mathrm{HA}}} / \mathrm{s}^{2}{ }_{-} \mathrm{Agg}$ \\
\hline Explained by $\mathrm{T}(\mathrm{C}+\mathrm{E})$ & 0.062 & $0.008(0.005-0.013)$ & $0.037(0.023-0.051)$ & $0.016(0.010-0.017)$ \\
\hline
\end{tabular}

(CI-95: 0.532-0.744). Table 6 also contains the decomposition of standardized phenotypic Agg variance based on the regression models. In the $\mathrm{A}+\mathrm{D}$ part of the model, the total explained (broad-sense) genetic variance of $\mathrm{Agg}$ is $41.4 \%$, which is decomposed into $1.3 \%$ (InA; CI-95: 0.06-1.8\%), 31.6\% (HA; CI-95: 27.5-35.8\%), and $8.5 \%$ (CI-95: 6-10.8\%) due to the broad-sense genetic covariance between InA and HA. In the $\mathrm{C}+\mathrm{E}$ part of the model, the total explained environmental variance was $21.9 \%$. This is decomposed into $2.9 \%$ (InA; CI-95: 1.4-3.1\%), 13.3\% (HA; CI-95: $13.0-19.0 \%$ ), and 5.6\% (CI-95: 3.6-8.0\%) due to the environmental covariance of InA and HA. At the broad sense genetic and environmental levels, HA emerged as the better predictor (genetic: $31.6 \% / 41.4 \%=76 \%$; environmental $13.3 \% / 21.9 \%=61 \%)$.

To evaluate the predictive contributions to the phenotype variance of Agg, we standardized by the phenotypic variance (Table 6 bottom part). The total explained variance was $29.7 \%(\mathrm{~A}+\mathrm{D})+6.2 \%(\mathrm{C}+\mathrm{E})=35.9 \%$. As expected, this is almost equal to the percentage of explained variance in the phenotypic analyses (see above: $35.6 \%$ ). The $35.9 \%$ is decomposed as follows. $\mathrm{A}+\mathrm{D}$ contributed $0.9 \%$ due to genetic InA, $22.6 \%$ due to genetic $\mathrm{HA}, 6.1 \%$ due to the genetic covariance of InA and HA. C $+\mathrm{E}$ contributed $0.8 \%$ due to environmental In $\mathrm{A}, 3.7 \%$ due to environmental $\mathrm{HA}$, and $1.6 \%$ due to the environmental covariance between In A and HA. By far the best predictor is genetic HA, which accounted for $22.6 \% / 35.9 \%=63 \%$ of the phenotypic variance of Agg.
The remaining $37 \%$ is distributed over the other 5 remaining sources of variance.

\section{Combined Genetic Covariance Structure and Regression Analyses in Adults}

Table 3 includes the correlations between twins and among scales in the adult twins. The MZ twin correlations were 0.46 (Agg), 0.42 (InA), and 0.36 (HA). The DZ correlations were substantially lower: 0.17 (Agg), 0.20 (InA), and 0.13 (HA). In the genetic covariance structure model, we therefore included additive genetic (A), dominance genetic (D), and unique environmental (E) components. The estimates obtained in fitting the ADE model are given in Table 5 (bottom). The narrow sense heritabilities are 21\% (Agg), 31\% (InA), and 12\% (HA). The dominance variance components are relatively large: $26 \%$ (Agg), 13\% (InA), and 19\% (HA), giving rise to broad-sense heritabilities of $21+26=47 \%$ (Agg), $31+13=44 \%$ (InA), and $12+19=31 \%$ (HA). The unshared environmental variance is relatively large: $53 \%(\mathrm{Agg}), 56 \%(\mathrm{InA})$, and 62\% (HA). The estimates of the regression coefficients, for the phenotypic, genetic and non-genetic components in our model, are given in Table 7.

The effects of sex and age closely resembled the results of the phenotypic analysis (Table 4). The regression coefficients in the A+D part of the model were 0.399 for In A (CI-95: 0.374-0.485) and 0.276 for HA (CI =95: 0.149-0.395). In the E part of the model these were 0.201 
Table 7 Genetic $(\mathrm{G}(\mathrm{A}+\mathrm{D}))$ and environmental $(\mathrm{T}(\mathrm{E}))$ regression results in adults, where for both the genetic and environmental regression $\operatorname{Agg}_{\mathrm{i}}=\mathrm{b}_{0}+\mathrm{b}_{\mathrm{Sex}} * \operatorname{Sex}_{\mathrm{i}}+\mathrm{b}_{\mathrm{Age}} * \mathrm{Age}_{\mathrm{i}}+\mathrm{b}_{\mathrm{InA}} * \operatorname{InA}_{\mathrm{i}}+\mathrm{b}_{\mathrm{HA}} * \mathrm{HA}_{\mathrm{i}}+\varepsilon_{\mathrm{i}}$

\begin{tabular}{|c|c|c|c|c|}
\hline \multicolumn{2}{|l|}{ Adults } & Agg & InA & HA \\
\hline \multicolumn{5}{|c|}{ Raw regression coefficients with standard errors (se) or CI-95 intervals in parentheses } \\
\hline \multicolumn{2}{|l|}{ Intercept $\left(\mathrm{b}_{0}\right)$} & $3.86($ se 0.126$)$ & $7.58($ se 0.133$)$ & 7.59 (se 0.123$)$ \\
\hline \multicolumn{2}{|l|}{$\operatorname{Sex}\left(b_{\text {sex }}\right)$} & $0.722($ se 0.090$)$ & $-0.024(\mathrm{se} 0.093)$ & $0.053($ se 0.086$)$ \\
\hline \multicolumn{2}{|l|}{ Age $\left(b_{\text {Age }}\right)$} & $-0.003($ se 0.003$)$ & $-0.036($ se 0.004$)$ & $-0.010($ se 0.003$)$ \\
\hline \multicolumn{2}{|c|}{$\mathrm{G}(\mathrm{A}+\mathrm{D})$ Agg on $\operatorname{In} \mathrm{A}\left(\mathrm{b}_{\mathrm{InA}}\right)$} & $0.399(0.374-0.485)$ & & \\
\hline \multicolumn{2}{|c|}{$\mathrm{G}(\mathrm{A}+\mathrm{D}) \mathrm{Agg}$ on $\mathrm{HA}\left(\mathrm{b}_{\mathrm{HA}}\right)$} & $0.276(0.149-0.395)$ & & \\
\hline \multicolumn{2}{|l|}{$\mathrm{T}$ (E) $\mathrm{Agg}$ on $\operatorname{In} \mathrm{A}\left(\mathrm{b}_{\mathrm{InA}}\right)$} & $0.201(0.169-0.256)$ & & \\
\hline \multicolumn{2}{|l|}{$\mathrm{T}(\mathrm{E}) \mathrm{Agg}$ on $\mathrm{HA}\left(\mathrm{b}_{\mathrm{HA}}\right)$} & $0.118(0.055-0.176)$ & & \\
\hline \multicolumn{5}{|c|}{ Proportions of explained phenotypic variance of Agg with CI-95 intervals in parentheses } \\
\hline \multirow{3}{*}{ Explained by G(A+D) } & Total genetic & $\mathrm{b}_{\mathrm{G}_{-} \mathrm{InA}}{ }^{2 *} \mathrm{~s}_{\mathrm{G}}{ }^{2} \mathrm{InA} / \mathrm{s}_{\mathrm{G}}{ }^{2} \_\mathrm{Agg}$ & $\mathrm{b}_{\mathrm{G}_{-} \mathrm{HA}}{ }^{2} *_{\mathrm{s}_{\mathrm{G}}{ }^{2} \mathrm{AA}} / \mathrm{s}_{\mathrm{G}}{ }^{2} \mathrm{Agg}$ & $2 * \mathrm{~b}_{\mathrm{G} \_\mathrm{HA}} * \mathrm{~b}_{\mathrm{G} \_\mathrm{InA}} * \mathrm{~s}_{\mathrm{G} \_ \text {InA,HA }} / \mathrm{s}_{\mathrm{G}}{ }^{2} \_\mathrm{Agg}$ \\
\hline & 0.348 & $0.184(0.108-0.265)$ & $0.062(0.050-0.110)$ & $0.101(0.068-0.129)$ \\
\hline & Total environ & 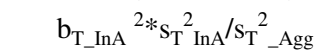 & $\mathrm{b}_{\mathrm{T} \_\mathrm{HA}}{ }^{2} *_{\mathrm{s}_{\mathrm{T}}{ }_{\mathrm{HA}}}^{2} / \mathrm{s}_{\mathrm{T} \_\mathrm{Agg}}^{2}$ & $2 * \mathrm{~b}_{\mathrm{T} \_\mathrm{HA}} * \mathrm{~b}_{\mathrm{T} \_ \text {InA }} * \mathrm{~s}_{\mathrm{T} \_\mathrm{InA}, \mathrm{HA}} / \mathrm{s}_{\mathrm{T}}{ }^{2}$ Agg \\
\hline \multirow[t]{2}{*}{ Explained by $\mathrm{T}(\mathrm{E})$} & 0.164 & $0.052(0.052-0.069)$ & $0.017(0.016-0.040)$ & $0.024(0.013-0.029)$ \\
\hline & Total phenot & $\mathrm{b}_{\mathrm{G} \_ \text {InA }}{ }^{2}{ }^{\mathrm{s}_{\mathrm{G}} \mathrm{InA}^{2}} / \mathrm{s}^{2}{ }_{\mathrm{Agg}}$ & $\mathrm{b}_{\mathrm{G} \_\mathrm{InA}}{ }^{2 *} \mathrm{~s}_{\mathrm{G}}^{2}{ }_{\mathrm{InA}} / \mathrm{s}^{2}{ }_{\text {Agg }}$ & $2 * \mathrm{~b}_{\mathrm{G} \_\mathrm{HA}} * \mathrm{~b}_{\mathrm{G} \_ \text {InA }} * \mathrm{~s}_{\mathrm{G}_{\_} \mathrm{InA}, \mathrm{HA}} / \mathrm{s}^{2}{ }_{-\mathrm{Agg}}$ \\
\hline \multirow[t]{2}{*}{ Explained by G(A+D) } & 0.162 & $0.086(0.055-0.124)$ & $0.029(0.009-0.061)$ & $0.047(0.029-0.061)$ \\
\hline & & $\mathrm{b}_{\mathrm{T}_{-} \text {InA }}{ }^{2 *} \mathrm{~s}_{\mathrm{T}}{ }^{2}$ InA $/ \mathrm{s}^{2}{ }_{-\mathrm{Agg}}$ & $\mathrm{b}_{\mathrm{T}_{-} \mathrm{HA}}{ }^{2} *_{\mathrm{T}_{\mathrm{T}} \mathrm{HA}^{2}} / \mathrm{s}^{2}{ }_{-} \mathrm{Agg}$ & $2 * \mathrm{~b}_{\mathrm{T} \_\mathrm{HA}} * \mathrm{~b}_{\mathrm{T} \_ \text {InA }}{ }^{*} \mathrm{~s}_{\mathrm{T}_{-} \text {InA }, \mathrm{HA}} / \mathrm{s}^{2}{ }_{-} \mathrm{Agg}$ \\
\hline Explained by $\mathrm{T}(\mathrm{E})$ & 0.049 & $0.027(0.020-0.027)$ & $0.009(0.008-0.010)$ & $0.013(0.010-0.014)$ \\
\hline
\end{tabular}

for InA (CI-95: 0.169-0.256) and 0.118 for HA (CI-95: 0.055-0.176). Table 7 also contains the decomposition of standardized phenotype Agg variance based on the regression models. In the $\mathrm{A}+\mathrm{D}$ part of the model, the total explained (broad-sense) genetic variance of Agg was $34.8 \%$, which is decomposed into $18.4 \%$ (InA; CI-95: 10.8-26.5\%), 6.2\% (HA; CI-95: 5-11\%), and 10.1\% (CI95: $6.8-12.9 \%$ ), due to the broad-sense genetic covariance between InA and HA. In the E part of the model, the total explained environmental variance was $16.4 \%$. This is decomposed into 5.2\% (InA; CI-95: 5.2-6.9\%), 1.7\% (HA; CI-95: $1.6-4 \%$ ), and 2.4\% (CI-95: 1.3-2.9\%) due to the environmental covariance of InA and HA. At the broad sense genetic and environmental levels, InA emerges as the better predictor (genetic: $18.4 \% / 34.8 \%=53 \%$; environmental $5.2 \% / 16.4 \%=32 \%$ ).

To evaluate the predictive contributions to the phenotype variance of Agg, we standardized by the phenotypic variance (Table 7 bottom part). The total explained variance was $16.2 \%(\mathrm{~A}+\mathrm{D})+4.9 \%(\mathrm{E})=21 \%$. As expected this resembles the percentage of the explained variance in the phenotypic analyses (as mentioned above: $18.6 \%$ ). The $21 \%$ is decomposed as follows. $\mathrm{A}+\mathrm{D}$ contributes $8.6 \%$ due to genetic InA, $2.9 \%$ due to genetic $\mathrm{HA}, 4.7 \%$ due to the genetic covariance of InA and HA. E contributes $2.7 \%$ due to environmental InA, $0.9 \%$ due to environmental HA, and 1.3\% due to the environmental covariance between InA and HA. By far the best predictor is genetic InA, which accounts for $8.6 \% / 21 \%=41 \%$ of the phenotypic variance of $\mathrm{Agg}$.

\section{Discussion}

In this contribution, we integrated a regression model within genetic covariance modeling. We applied the model to data from children and adults to address the question of differential prediction of aggression (Agg) by two components of ADHD, i.e. inattention (InA) and hyperactivity (HA). These types of questions of a best genetic predictor of an outcome trait or disease may come up in multiple contexts, such as the prediction of educational attainment by cognitive ability and non-cognitive skills (Demange et al. 2020) or hypertension and cardiovascular outcomes by multiple correlated factors (Lucaroni et al. 2019).

Also, the integrated model that we presented can be applied beyond the classical twin design to any genetically informative dataset or design that allows estimation of genetic and a non-genetic covariance matrices, including adoption or family studies and single-nucleotide polymorphism (SNP) based approaches to infer heritability and genetic covariance matrices from GWA studies or from their summary statistics. The possibility to consider ADCE models, rather than limiting to e.g., AE or ACE, depends on the study design and the appropriate identifying constraints. In our model for twin data these constraints involved specifying a one-factor model for the common environmental influences and the absence of genetic dominance for 1 of the 3 phenotype outcomes. We note that the present approach of estimating genetic and environmental covariance matrices, and simultaneously modeling these, differs slightly from 
the standard multivariate genetic covariance structure modeling where genetic and environmental covariance matrices are subjected directly to a structural equation model (e.g., a growth curve model, autoregressive model, or a common factor model). However, the present approach allows us to fit the model of interest (i.e., the regression model) to the broad-sense genetic $(\mathrm{A}+\mathrm{D})$ and the total environmental $(\mathrm{C}+\mathrm{E})$ covariance matrices, provided that these are positive definite.

Application of these methods produced a clear set of results concerning the prediction of aggression in children and in adults. In children, genetic hyperactivity was without doubt the stronger predictor of aggression, after taking into account the effects of inattention and the shared covariance of hyperactivity and inattention. A stronger predictive value of HA for aggression in children is consistent with several lines of research. There is evidence of different neural correlates of ADHD with predominantly hyperactive-impulsive, predominantly inattentive and the combined subtype (Saad et al. 2017). Hyperactivity is a stronger predictor of conduct problems than inattention in girls with ADHD (Lee and Hinshaw 2006). The information on 10-year old twins was collected from maternal ratings, and rater effects could have contributed to the results that were obtained. Vierikko et al. (2004) assessed the relation between aggression and hyperactivity/impulsivity from parents in the home situation and from teachers in the classroom. They report high genetic correlations between aggression and hyperactivity both when analyses were based on teacher and on parental ratings.

The results obtained in the analyses of adult self-ratings led to different conclusions concerning the prediction of aggression: genetic inattention clearly was the better predictor of aggression, again after considering the effects of hyperactivity and the covariance of hyperactivity and inattention. We note, however, that the adult dataset included self-report measures collected at different points in time. Still, assuming the test-retest reliability of the inattention test and the hyperactivity are about the same in adults, the difference in measurement occasion would not explain the relatively stronger role of inattention.

In conclusion, our genetic modeling of the trivariate twin data provided an insight into the genetic and non-genetic predictors of aggression. Standard Cholesky decompositions are commonly used to obtain estimates of genetic and environmental covariance matrices. We note that the Cholesky parameterization itself can be used as a regression model (with the dependent variable as the last variable; e.g., de Jong 1999). However, the present approach has the advantage of basing the regression model on the $\mathrm{A}+\mathrm{D}$ and the $\mathrm{C}+\mathrm{E}$ covariance matrices, which is useful if the covariances matrices (A and/or D, C and/or E) are (near) singular. In that case, we consider the option to be able to address the prediction issue at the broad-sense genetic or total environmental level to be a worthwhile one. In addition, our present approach to regression modeling in OpenMx allows a decomposition of the variance of the dependent variable (Aggression) into raw and standardized variance components. We carried out the ACDE decomposition and regression analysis separately in children and adults, with age and sex as fixed covariates. We note that the present implementation of the regression model in genetic covariance structure modeling can be extended to include fixed covariates as moderators of the regression parameters. For instance, in our adult data the mean age is $\sim 30$ years, but the variation in age is quite large (SD: 12.5). The present approach to the regression analysis can be extended to include age as a continuous moderator. We included the regression of aggression on HA and InA at the genetic and environmental level and obtained estimates of the phenotypic, genetic, and environmental variance components standardized by the total phenotypic variance, which revealed the relative contributions of genetic and environmental factors to the phenotypic regression of aggression on hyperactivity and inattention.

Acknowledgements we warmly thank all participants who donate their time to the Netherlands Twin Register research projects. We acknowledge funding from the Borderline Personality Disorder Research Foundation; ZonMW (31160008), the European Research Council (ERC-230374), NWO (480-15-001/674): Netherlands Twin Registry Repository; the European Union Seventh Framework Program (FP7/2007-2013) grant agreement 602768: "Aggression in Children: Unraveling gene-environment interplay to inform Treatment and InterventiON strategies" (ACTION); National Institute on Drug Abuse grant DA049867; and the KNAW Academy Professor Award (PAH/6635) to DIB. We thank Sofieke Kevenaar for her comments on the paper.

\section{Compliance with Ethical Standards}

Conflict of interest Dorret I. Boomsma, Toos C. E. M. van Beijsterveldt, Veronika Odintsova, Michael C. Neale, Conor V. Dolan declare that they have no conflict of interest.

Ethical Approval All procedures performed in studies involving human participants were in accordance with the ethical standards of the institutional and/or national research committee and with the 1964 Helsinki declaration and its later amendments or comparable ethical standards. The studies were approved by the Central Ethics Committee on Research Involving Human Subjects of the VU University Medical Center, Amsterdam, an Institutional Review Board certified by the U.S. Office of Human Research Protections (IRB number IRB-2991 under Federal-wide Assurance-3703).

Informed Consent Informed consent was obtained for all participants.

Open Access This article is licensed under a Creative Commons Attribution 4.0 International License, which permits use, sharing, adaptation, distribution and reproduction in any medium or format, as long as you give appropriate credit to the original author(s) and the source, provide a link to the Creative Commons licence, and indicate if changes were made. The images or other third party material in this article are included in the article's Creative Commons licence, unless indicated 
otherwise in a credit line to the material. If material is not included in the article's Creative Commons licence and your intended use is not permitted by statutory regulation or exceeds the permitted use, you will need to obtain permission directly from the copyright holder. To view a copy of this licence, visit http://creativecommons.org/licenses/by/4.0/.

\section{References}

Achenbach TM, Ivanova MY, Rescorla LA (2017) Empirically based assessment and taxonomy of psychopathology for ages $1 \frac{1 / 2-90+}{2}$ years: developmental, multi-informant, and multicultural findings. Compr Psychiatry 79:4-18

Andersson A, Tuvblad C, Chen Q, Du Rietz E, Cortese S, Kuja-Halkola R, Larsson HJ (2020) Research review: the strength of the genetic overlap between ADHD and other psychiatric symptoms-a systematic review and meta-analysis. J Child Psychol Psychiatry. https://doi.org/10.1111/jcpp.13233

Bartels M, Hendriks A, Mauri M, Krapohl E, Whipp A, Bolhuis K, Conde LC, Luningham J, Ip HF, Hagenbeek F, Roetman P, Gatej R, Lamers A, Nivard M, van Dongen J, Lu Y, Middeldorp C, van Beijsterveldt T, Vermeiren R, Hankemeijer T, Kluft C, Medland S, Lundström S, Rose R, Pulkkinen L, Vuoksimaa E, Korhonen T, Martin NG, Lubke G, Finkenauer C, Fanos V, Tiemeier H, Lichtenstein P, Plomin R, Kaprio J, Boomsma DI (2018) Childhood aggression and the co-occurrence of behavioural and emotional problems: results across ages 3-16 years from multiple raters in six cohorts in the EU-ACTION project. Eur Child Adolesc Psychiatry 27(9):1105-1121

Biederman J, Newcorn J, Sprich S (1991) Comorbidity of attention deficit hyperactivity disorder with conduct, depressive, anxiety, and other disorders. Am J Psychiatry 148:564-577

Boomsma DI, Vink JM, van Beijsterveldt TC, de Geus EJ, Beem AL, Mulder EJ, Derks EM, Riese H, Willemsen GA, Bartels M, van den Berg M, Kupper NH, Polderman TJ, Posthuma D, Rietveld MJ, Stubbe JH, Knol LI, Stroet T, van Baal GC (2002) Netherlands twin register: a focus on longitudinal research. Twin Res 5(5):401-406

Brezinski C (2005) La méthode de Cholesky. Revue d'Histoire des Mathématiques 11(2):205-238

Conners CK, Erhardt D, Sparrow E (1999) Conners' adult ADHD rating scales (CAARS). Multi-Health systems Inc, North Tonawanda, NY, p 144

Conners CK (2001) Conners' rating scales-revised. Multi-Health Systems Inc, NY, Toronto

Conners CK, Sitarenios G, Parker JD, Epstein JN (1998) The revised conners' parent rating scale (CPRS-R): factor structure, reliability, and criterion validity. J Abnorm Child Psychol 26:257-268

Connor DF, Chartier KG, Preen EC, Kaplan RF (2010) Impulsive aggression in attention-deficit/hyperactivity disorder: symptom severity, co-morbidity, and attention-deficit/hyperactivity disorder subtype. J Child Adolesc Psychopharmacol 20(2):119-126

de Jong PF (1999) Hierarchical regression analysis in structural equation modeling. Struct Eqn Model 6(2):198-211

Demange PA et al (2020) Parental influences on offspring education: indirect genetic effects of non-cognitive skills. biorxiv. https://doi. org/10.1101/2020.09.15.296236

Derks EM, Hudziak JJ, Dolan CV, van Beijsterveldt TC, Verhulst FC, Boomsma DI (2008) Genetic and environmental influences on the relation between attention problems and attention deficit hyperactivity disorder. Behav Genet 38(1):11-23

Derks EM, Hudizak JJ, Boomsma DI (2009) Genetics of ADHD, hyperactivity, and attention problems. In: Yong-Kyu K (ed) Handbook of behavior genetics. Springer, NY, pp 361-378
Distel MA, Ligthart L, Willemsen G, Nyholt DR, Trull TJ, Boomsma DI (2007) Personality, health and lifestyle in a questionnaire family study: a comparison between highly cooperative and less cooperative families. Twin Res Hum Genet 10(2):348-353

Dolan CV, de Zeeuw EL, Zayats T, van Beijsterveldt CEM, Boomsma DI (2020) The (Broad-Sense) genetic correlations among four measures of inattention and hyperactivity in 12 year olds. Behav Genet 50(4):273-288

Duffy DL, Martin NG (1994) Inferring the direction of causation in cross-sectional twin data: theoretical and empirical considerations. Genet Epidemiol 11(6):483-502

Faraone SV, Larsson H (2019) Genetics of attention deficit hyperactivity disorder. Mol Psychiatry 24(4):562-575

Faries DE, Yalcin I, Harder D, Heiligenstein JH (2001) Validation of the ADHD rating scale as a clinician administered and scored instrument. J Atten Disord 5(2):107-115

Franić S, Dolan CV, Borsboom D, Boomsma DI (2012) Structural equation modeling in genetics. In: Hoyle R (ed) Handbook of structural equation modeling. Guilford Press, NY, pp 617-635

Franić S, Dolan CV, Borsboom D, Hudziak JJ, van Beijsterveldt CE, Boomsma DI (2013) Can genetics help psychometrics? Improving dimensionality assessment through genetic factor modeling. Psychol Methods 18(3):406-433

Franke B, Michelini G, Asherson P, Banaschewski T, Bilbow A, Buitelaar JK, Cormand B, Faraone SV, Ginsberg Y, Haavik J, Kuntsi J, Larsson H, Lesch KP, Ramos-Quiroga JA, Réthelyi JM, Ribases M, Reif A (2018) Live fast, die young? a review on the developmental trajectories of ADHD across the lifespan. Eur Neuropsychopharmacol 28(10):1059-1088

Geels LM, Vink JM, van Beek JH, Bartels M, Willemsen G, Boomsma DI (2013) Increases in alcohol consumption in women and elderly groups: evidence from an epidemiological study. BMC Public Health 13:207

Hagenbeek FA, van Dongen J, Kluft C, Hankemeier T, Ligthart L, Willemsen G, de Geus EJC, Vink JM, Bartels M, Boomsma DI (2018) Adult aggressive behavior in humans and biomarkers: a focus on lipids and methylation. J Pediatr Neonat Indivd Med 7(2):e070204

Hamshere ML, Langley K, Martin J, Agha SS, Stergiakouli E, Anney RJ, Buitelaar J, Faraone SV, Lesch KP, Neale BM, Franke B, Sonuga-Barke E, Asherson P, Merwood A, Kuntsi J, Medland SE, Ripke S, Steinhausen HC, Freitag C, Reif A, Renner TJ, Romanos M, Romanos J, Warnke A, Meyer J, Palmason H, Vasquez AA, Lambregts-Rommelse N, Roeyers H, Biederman J, Doyle AE, Hakonarson $\mathrm{H}$, Rothenberger A, Banaschewski T, Oades RD, McGough JJ, Kent L, Williams N, Owen MJ, Holmans P, O'Donovan MC, Thapar A (2013) High loading of polygenic risk for ADHD in children with comorbid aggression. Am J Psychiatry 170(8):909-916

Heath AC, Kessler RC, Neale MC, Eaves LJ, Kendler KS (1993) Testing hypotheses about direction of causation using cross-sectional family data. Behav Genet 23:29-50

Hinshaw SP (1992) Externalizing behavior problems and academic underachievement in childhood and adolescence: causal relationships and underlying mechanisms. Psychol Bull 111:127-155

Hinshaw SP, Owens EB, Sami N, Fargeon S (2006) Prospective follow-up of girls with attention-deficit/hyperactivity disorder into adolescence: Evidence for continuing cross-domain impairment. J Consult Clin Psychol 74(3):489-499

Hur YM (2015) Genetic and environmental etiology of the relationship between childhood hyperactivity/inattention and conduct problems in a South Korean twin sample. Twin Res Hum Genet 18(3):290-297

Ip HF et al (2019) Genetic association study of childhood aggression across raters, instruments and age. BioRxiv. https://doi. org/10.1101/854927 
Jensen PS, Martin D, Cantwell DP (1997) Comorbidity in ADHD: implications for research, practice, and DSM-V. J Am Acad Child Adolesc Psychiatry 36:1065-1079

Lee SS, Hinshaw SP (2006) Predictors of adolescent functioning in girls with attention deficit hyperactivity disorder (ADHD): the role of childhood ADHD, conduct problems, and peer status. J Clin Child Adolesc Psychol 35(3):356-368

Ligthart L, van Beijsterveldt CEM, Kevenaar ST, de Zeeuw E, van Bergen E, Bruins S, Pool R, Helmer Q, van Dongen J, Hottenga JJ, Van't Ent D, Dolan CV, Davies GE, Ehli EA, Bartels M, Willemsen G, de Geus EJC, Boomsma DI (2019) The Netherlands twin register: longitudinal research based on twin and twin-family designs. Twin Res Hum Genet 22(6):623-636

Lucaroni F, Cicciarella Modica D, Macino M, Palombi L, Abbondanzieri A, Agosti G, Biondi G, Morciano L, Vinci A (2019) Can risk be predicted? an umbrella systematic review of current risk prediction models for cardiovascular diseases, diabetes and hypertension. BMJ Open 9(12):e030234

Martin NG, Eaves LJ (1977) The genetical analysis of covariance structure. Heredity (Edinb) 38(1):79-95

Neale MC, Eaves LJ, Hewitt JK, Kendler KS (1994) Multiple regression with data collected from relatives: testing assumptions of the model. Multivar Behav Res 29:33-61

Neale MC, Hunter MD, Pritikin JN, Zahery M, Brick TR, Kirkpatrick RM, Estabrook R, Bates TC, Maes HH, Boker SM (2016) OpenMx 20: extended structural equation and statistical modeling. Psychometrika 81(2):535-549

Odintsova VV, Roetman PJ, Ip HF, Pool R, Van der Laan CM, Tona KD, Vermeiren RRJM, Boomsma DI (2019) Genomics of human aggression: current state of genome-wide studies and an automated systematic review tool. Psychiatr Genet 29(5):170-190

Ozaki K, Toyoda H, Iwama N, Kubo S, Ando J (2011) Using nonnormal SEM to resolve the ACDE model in the classical twin design. Behav Genet 41(2):329-339

Porsch RM, Middeldorp CM, Cherny SS, Krapohl E, van Beijsterveldt CE, Loukola A, Korhonen T, Pulkkinen L, Corley R, Rhee S, Kaprio J, Rose RR, Hewitt JK, Sham P, Plomin R, Boomsma DI, Bartels M (2016) Longitudinal heritability of childhood aggression. Am J Med Genet B 171(5):697-707

Purcell S (2002) Variance components models for gene-environment interaction in twin analysis. Twin Res 5(6):554-571
Saad JF, Griffiths KR, Kohn MR, Clarke S, Williams LM, Korgaonkar MS (2017) Regional brain network organization distinguishes the combined and inattentive subtypes of attention deficit hyperactivity disorder. Neuroimage Clin 15:383-390

Saviouk V, Hottenga JJ, Slagboom EP, Distel MA, de Geus EJ, Willemsen G, Boomsma DI (2011) ADHD in Dutch adults: heritability and linkage study. Am J Med Genet B 156B(3):352-362

Sokolova E, Groot P, Claassen T, van Hulzen KJ, Glennon JC, Franke B, Heskes T, Buitelaar J (2016) Statistical evidence suggests that inattention drives hyperactivity/impulsivity in attention deficithyperactivity disorder. PLoS ONE 11(10):e016512

van Beijsterveldt CE, Bartels M, Hudziak JJ, Boomsma DI (2003) Causes of stability of aggression from early childhood to adolescence: a longitudinal genetic analysis in Dutch twins. Behav Genet 33(5):591-605

van Beijsterveldt CE, Groen-Blokhuis M, Hottenga JJ, Franić S, Hudziak JJ, Lamb D, Huppertz C, de Zeeuw E, Nivard M, Schutte N, Swagerman S, Glasner T, van Fulpen M, Brouwer C, Stroet T, Nowotny D, Ehli EA, Davies GE, Scheet P, Orlebeke JF, Kan KJ, Smit D, Dolan CV, Middeldorp CM, de Geus EJ, Bartels M, Boomsma DI (2013) The Young Netherlands Twin Register (YNTR): longitudinal twin and family studies in over 70,000 children. Twin Res Hum Genet 16(1):252-267

Vierikko E, Pulkkinen L, Kaprio J, Rose RJ (2004) Genetic and environmental influences on the relationship between aggression and hyperactivity-impulsivity as rated by teachers and parents. Twin Res 7(3):261-274

Vuoksimaa E, Rose RJ, Pulkkinen L, Palviainen T, Rimfeld K, Lundström S, Bartels M, van Beijsterveldt C, Hendriks A, de Zeeuw EL, Plomin R, Lichtenstein P, Boomsma DI, Kaprio J (2020) Higher aggression is related to poorer academic performance in compulsory education. J Child Psychol Psychiatry. https://doi. org/10.1111/jcpp. 13273

Willcutt EG, Nigg JT, Pennington BF, Solanto MV, Rohde LA, Tannock R, Loo SK, Carlson CL, McBurnett K, Lahey BB (2012) Validity of DSM-IV attention deficit/hyperactivity disorder symptom dimensions and subtypes. J Abnorm Psychol 121(4):991-1010

Publisher's Note Springer Nature remains neutral with regard to jurisdictional claims in published maps and institutional affiliations. 